\title{
PROGRAM BOLTZMANN TEMPERATURE DEPEDENCE UNTUK MENENTUKAN TEMPERATUR BAWAH PERMUKAAN AREA GEOTHERMAL MENGGUNAKAN DATA RESISTIVITAS
}

\author{
*Mohammad Hasib \\ Pusat Penelitian Fisika - LIPI, \\ Kawasan PUSPIPTEK Serpong, \\ Banten 15314 \\ mohammadhasib07@gmail.com \\ Sukir Maryanto \\ Universitas Brawijaya Malang \\ smaryanto@gmail.com
}

*koresponden author
Abstrak - Penentuan temperatur bawah permukan merupakan hal penting diperlukan untuk mengetahui seberapa besar potensi geothermal pada suatu area. Saat ini belum ada penelitian yang berfokus pada pengembangan program yang dapat dijadikan referensi untuk mengkonversi parameter data resistivitas ke parameter temperatur batuan. Oleh karena itu, penting dilakukan pengembangan program untuk mengetahui temperatur bawah permukaan bumi berdasarkan data resistivitas. Input program adalah data resistivitas dalam Ohm.Meter, dan output program adalah temperatur dalam Celsius. Dalam perhitungannya, program menggunakan persamaan ketergantungan suhu Boltzmann untuk perhitungan suhu batuan dengan pendekatan metode biseksi. Berdasarkan hasil uji validitas teoretis dan eksperimen, program memungkinkan dapat dijadikan referensi dalam penentuan parameter temperatur batuan dari parameter input nilai resistivitas batuan. Program memiliki beberapa kelebihan yaitu mudah dioperasikan, dan rendahnya error antara hasil program dan hasil teoretis. Penelitian ini dapat memberikan pilihan program bagi peneliti untuk mengetahui nilai temperatur batuan dari nilai resitivitas untuk mengetahui potensi panas bumi di bawah permukaan.

Kata Kunci : Program ketergantungan temperatur Boltzman, Panas bumi, Temperatur, Data resistivitas.

\begin{abstract}
Estimation of the sub-surface temperature is important to determine how much geothermal potential in an area. There is no research that focuses on development of program as a reference for converting resistivity data parameters to rock temperature parameters. Therefore, it's important to develop a program to determine the subsurface temperatures based on resistivity data. The program input is the resistivity data in Ohm.Meter, and the program output is the temperature in Celsius. In the calculation, the program uses the Boltzmann temperature dependence equation for calculating rock temperature using the bisection method approach. Based on the theoretical and experimental validity test, the program may be applied as a reference in determining the rock temperature parameter from the rock resistivity parameter. The program has several advantages, namely easy to operate, and low error between the program and theoretical results. This research can provide a choice for researchers to determine the rock temperature parameter from the resistivity parameter to determine the sub-surface geothermal potential.
\end{abstract}

Keywords : Boltzmann Temperature Depedence Program, Geothermal, Temperature, Resistivity data. 


\section{A. PENDAHULUAN}

Potensi sumber panas bumi (geotermal) di Indonesia sangatlah besar dengan perkiraan potensi sebesar $\pm 40 \%$ dari cadangan dunia yaitu 25.875 MW (Direktorat Jenderal Geologi dan Sumber Daya Mineral, 2004). Potensi tersebut membentang dari Sumatra, Jawa, Nusa Tenggara, Sulawesi sampai Maluku (Rina Wahyuningsih, 2005). Namun, hal tersebut berbanding terbalik dengan kondisi pemanfaatan panas bumi yang masih minimal. Padahal pemanfaatan energi panas bumi di masa depan sangat dibutuhkan. Mengingat pemakaian sumber energi konvensional (minyak bumi/batu bara) untuk pembangunan diprediksi tidak mencukupi (Herman, 2012). Oleh sebab itu, perlu dilakukan studi/penelitian yang mendukung proses identifikasi potensi panas bumi.

Nilai resistivitas yang diperoleh melalui pengukuran metode geofisika seperti metode geolistrik atau magnetik di lapangan tidaklah mudah untuk mengetahui potensi panas bumi di suatu area secara langsung. Oleh sebab itu, diperlukan pengolahan data resistivitas lebih lanjut untuk memudahkan peneliti/interpreter dalam mengidentifikasi potensi sumber panas bumi di suatu area. Pada penelitian ini, penulis melakukan pemograman untuk mengkonversi data resistivitas ke suhu/temperatur batuan berdasarkan persamaan matematis. Tujuan penelitian adalah menentukan temperatur batuan berdasarkan nilai resistivitas yang dijadikan acuan informasi untuk mengetahui potensi panas bumi di suatu daerah. Diharapkan penelitian ini dapat memberikan referensi untuk mengkonversi nilai data resistivitas yang dapat memudahkan peneliti dalam proses identifikasi potensi panas bumi di suatu area.

\section{B. METODE}

Dalam hubungan dengan parameter resitivitas, persamaan Boltzmann dapat di nyatakan sebagai fungsi ekponensial dari energi dan temperatur (lihat Persamaan 1) (Keller, 1975).

$$
\rho^{-1}=\sigma=\mathrm{A}_{1} \mathrm{e}^{-\mathrm{U} 1 / \mathrm{kT}}+\mathrm{A}_{2} \mathrm{e}^{-\mathrm{U} 2 / \mathrm{kT}} \quad \ldots(1)
$$

Dengan, $\rho$ merupakan resistivitas (ohm-m); $\sigma$ merupakan konduktivitas $(\mathrm{S} / \mathrm{m}) ; \mathrm{A}_{1}, \mathrm{~A}_{2}$ merupakan konduktivitas pada $\mathrm{T}=0(\mathrm{~s} / \mathrm{m}) ; \mathrm{U} 1, \mathrm{U} 2$ merupakan energi aktivatsi $(\mathrm{eV})$; T merupakan temperatur $(\mathrm{K})$; $\mathrm{K}$ merupakan konstanta Boltzmannt (eV/K).

Persaman (1) digunakan sebagai persamanan fungsi dalam pembuatan program pada penelitian ini untuk menentukan parameter temperatur batuan (output) dari parameter nilai resistivitas suatu batuan (input). 


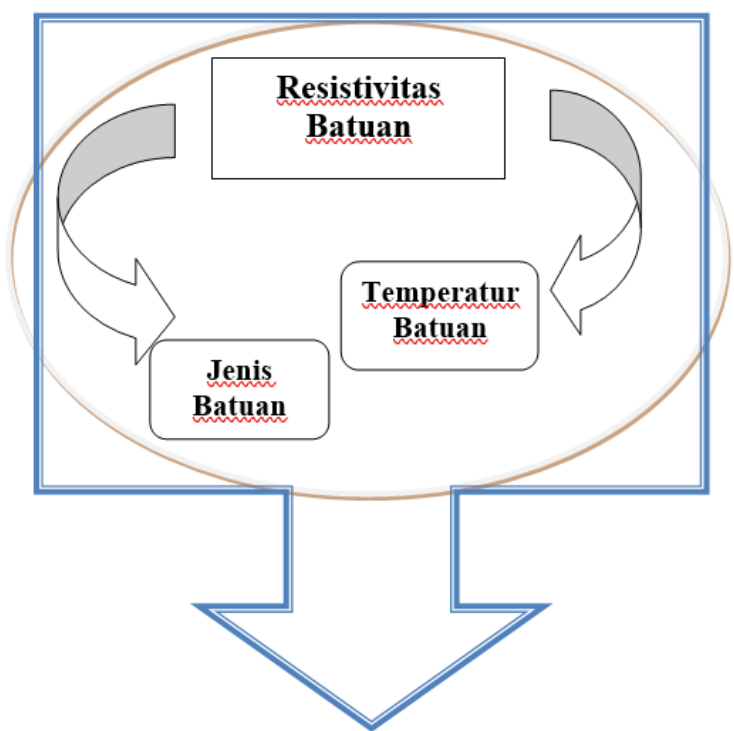

\section{Area potensi geotermal}

Gambar 1. Konsep dasar penelitian

Konsep dari penelitian adalah data resistivitas yang diperoleh di lapangan dan dengan mengetahui jenis batuan dari tabel resistivitas batuan, sehingga dapat diketahui temperatur batuan yang dialiri fluida panas dengan menggunakan program pada penelitian ini. Dari hasil tersebut dapat dijadikan referensi untuk diperoleh informasi seberapa besar potensi geothermal pada suatu daerah untuk dilakukan kegiatan eksplorasi (lihat Gambar 2.1).

Pada penelitian ini hanya dibatasi pada pada 5 jenis batuan yang sering dijumpai pada hidrotermal reservoar dan merupakan batuan vulkanik yang erat kaitannya dengan terjadinya manifestasi panas bumi (Khoirul, 2018; Andrie dkk, 2014; Saptadji, 2009). 


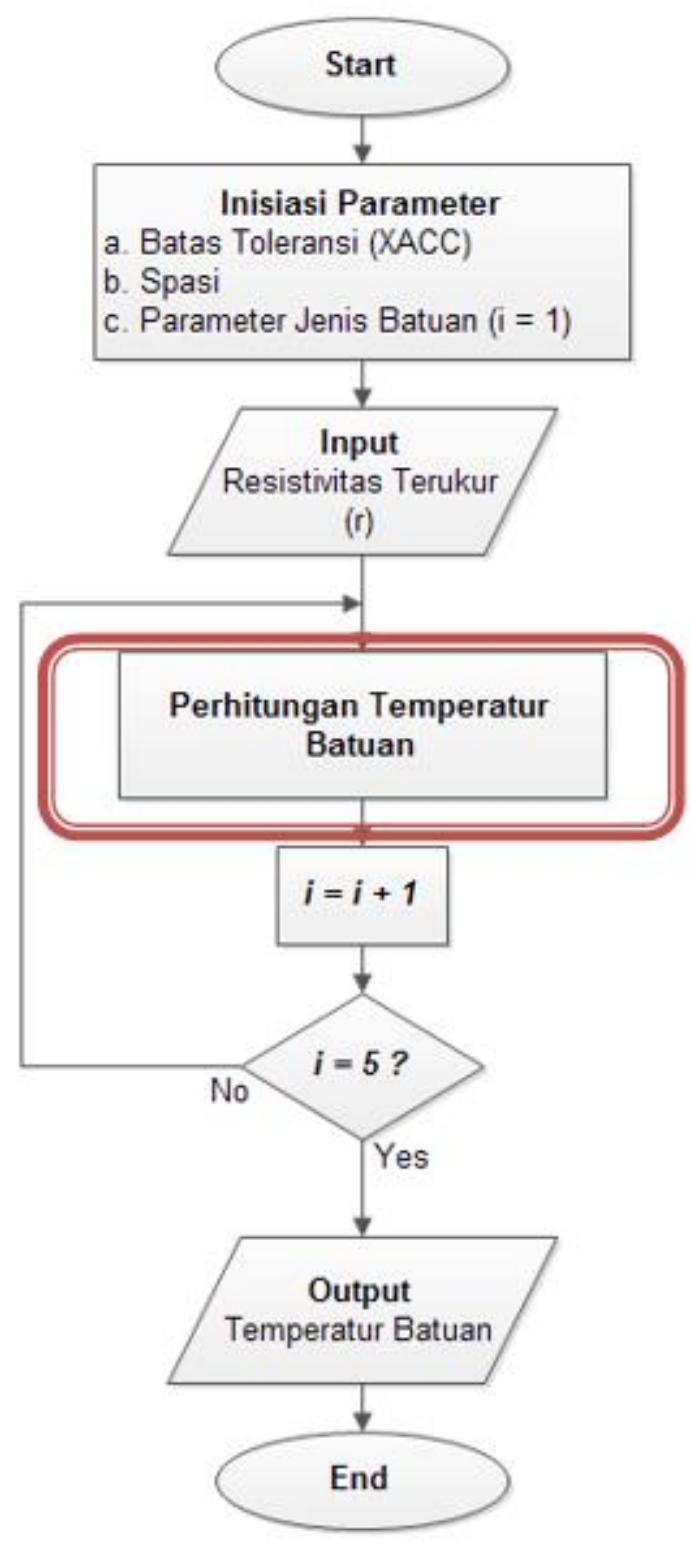

Gambar 2. Cara kerja program

Program dibuat menggunakan bahasa pemrograman Fortran dalam proses pembuatannya. Identifikasi temperatur batuan hanya terbatas pada lima jenis batuan (granite, gabbro, basalt, peridotite dan andesite), namun memungkinan untuk dilakukan penambahan jenis batuan yang lain, sesuai yang diinginkan. Input program adalah nilai resitivitas batuan. Perhitungan temperatur batuan dilakukan dengan menggunakan metode biseksi. Metode ini digunakan karena memiliki ketelitian/ keakurasian yang tinggi. Persamaan yang diaproksimasi akar-akarnya adalah persamaan Boltzmann Temperature Dependence. Dalam proses penentuan nilai temperatur batuan, program melakukan iterasi (lebih dari 1000 perulangan) hingga mencapai nilai error terkecil antara observasi dan teoretis. Program menampilkan output berupa temperatur untuk 5 jenis batuan yang teridentifikasi untuk setiap inputan 
nilai resitivitas batuan. Output yang dihasilkan berupa temperatur dalam satuan unit Celsius $\left({ }^{0} \mathrm{C}\right)$ (lihat Gambar 2.2).

\section{HASIL DAN PEMBAHASAN}

Dalam mengetahui kelayakan program, penulis melakukan beberapa uji validitas yang dapat dijadikan ukuran untuk mengetahui seberapa layak program tersebut dapat diaplikasikan. Uji validitas yang dilakukan pada penelitian ini antara lain; uji validitas dengan hasil teoretis dan uji validitas dengan hasil eksperimen.

1) Validasi dengan hasil teoretis

Uji validitas dilakukan dengan membandingkan output program dengan hasil perhitungan teoretis. Perbedaan nilai temperatur yang didapatkan berdasarkan perhitungan teoretis dengan perhitungan menggunakan program. Pada bagian ini, input parameter nilai resistivitas ditentukan sebesar $1500 \Omega m$. Nilai temperatur yang dibandingkan ditandai dengan kotak berwarna biru pada tiap 5 jenis batuan. Satuan unit temperatur pada perhitungan teoretis dan program adalah Celcius $\left({ }^{\circ} \mathrm{C}\right)$. Nilai persentase error temperatur antara hasil program dan teoretis didapatkan dengan membandingan antara selisih hasil temperatur perhitungan program dan perhitungan teoretis dengan nilai temperatur perhitungan teoretis dikalikan $100 \%$. Hasil perhitungan program dan teoretis menunjukkan bahwa nilai error temperatur antara hasil perhitungan program dan teoretis adalah sebesar $0.00043 \%, 0.00001 \%$, $0.00003 \%, 0.00034 \%$, dan $0.03856 \%$ untuk jenis batuan granite, gabbro, basalt, peridotite, dan andesite, secara berurutan (lihat Gambar 3.1). Hasil tersebut menunjukkan bahwa nilai error tergolong rendah dengan persentase $<0.04 \%$ pada 5 jenis batuan input. Hal ini menunjukkan program tersebut memiliki tingkat keakurasian hasil yang tinggi terhadap hasil perhitungan teoretis. Hal tersebut membuktikan bahwa secara teoretis program Boltzmann Temperature Dependence pada penelitian ini layak/dapat diaplikasikan untuk penentuan temperatur bawah permukaan dengan menggunakan data resistivitas. 


\section{1.a Granite}

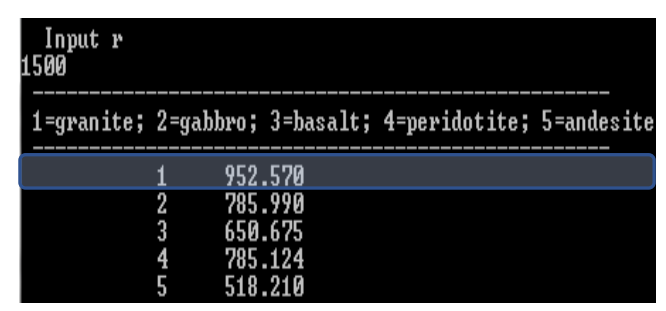

\begin{tabular}{ccc}
\hline Batuan & Temperatur $\left({ }^{\circ} \mathbf{C}\right)$ & Resistivitas $(\boldsymbol{\Omega m})$ \\
\hline Granite & 954.58 & 1500 \\
Gabbro & 954.58 & 100.76682 \\
Basalt & 954.58 & 15.888046 \\
Peridotite & 954.58 & 186.58217 \\
Andesite & 954.58 & 0.3790482 \\
\hline
\end{tabular}

\section{1.b Gabbro}

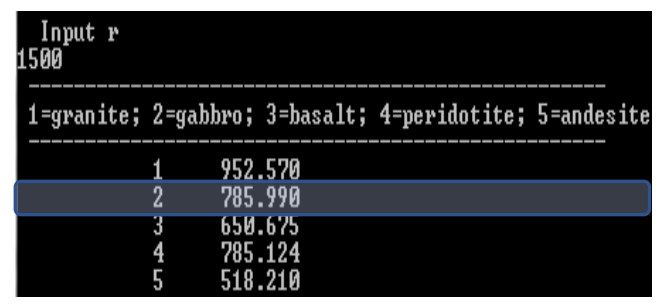

\begin{tabular}{ccc}
\hline Batuan & Temperatur $\left({ }^{\circ} \mathbf{C}\right)$ & Resistivitas $(\mathbf{\Omega m})$ \\
\hline Granite & 786 & 14540.841 \\
Gabbro & 786 & 1500 \\
Basalt & 786 & 227.31501 \\
Peridotite & 786 & 1485.804 \\
Andesite & 786 & 4.10227 \\
\hline
\end{tabular}

3.1.c

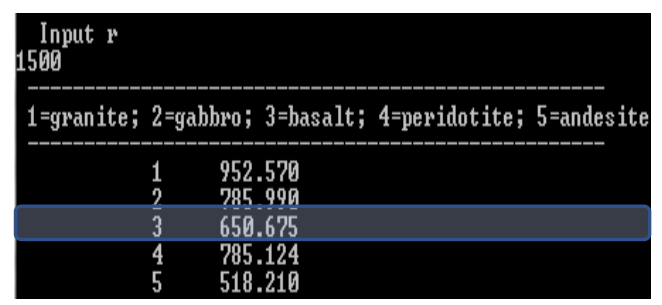

\begin{tabular}{ccc}
\hline Batuan & Temperatur $\left({ }^{\mathbf{0}} \mathbf{C}\right)$ & Resistivitas $(\mathbf{\Omega m})$ \\
\hline Granite & 650.69 & 47709.648 \\
Gabbro & 650.69 & 8605.9925 \\
Basalt & 650.69 & 1499.9996 \\
Peridotite & 650.69 & 6439.2502 \\
Andesite & 650.69 & 53.280859 \\
\hline
\end{tabular}

\section{1.d Peridotite}

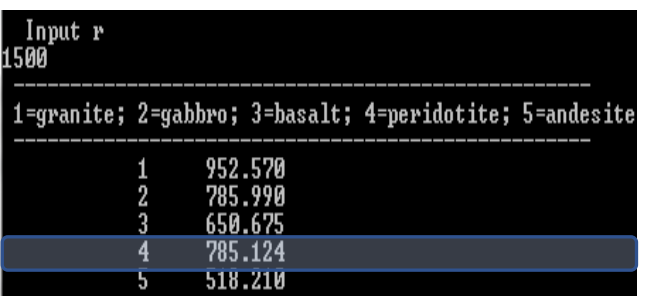

\begin{tabular}{ccc}
\hline Batuan & Temperatur $\left({ }^{\mathbf{O}} \mathbf{C}\right)$ & Resistivitas $(\mathbf{\Omega m})$ \\
\hline Granite & 785.13 & 14667.178 \\
Gabbro & 785.13 & 1519.7965 \\
Basalt & 785.13 & 230.51003 \\
Peridotite & 785.13 & 1499.995 \\
Andesite & 785.13 & 4.1615047 \\
\hline
\end{tabular}

\section{1.e}

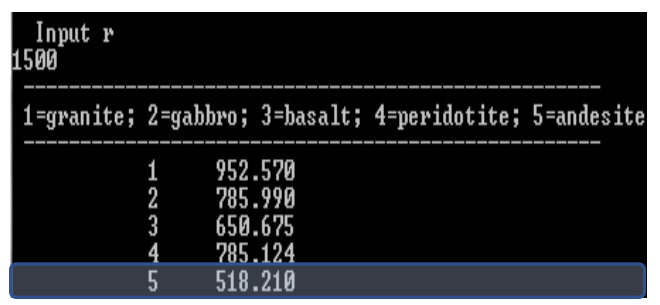

\begin{tabular}{ccc}
\hline Batuan & Temperatur $\left({ }^{\circ} \mathbf{C}\right)$ & Resistivitas $(\mathbf{\Omega m})$ \\
\hline Granite & 518.22 & 177609.48 \\
Gabbro & 518.22 & 40849.296 \\
Basalt & 518.22 & 6028.0841 \\
Peridotite & 518.22 & 35987.336 \\
Andesite & 518.22 & 1499.4218 \\
\hline
\end{tabular}

Gambar 3. Tampilan hasil perhitungan program (kiri) dan hasil perhitungan teoretis (kanan) untuk 5 jenis batuan dengan input tetap nilai resitivitas sebesar $1500 \Omega \mathrm{m}$ pada, a) granite, b) gabbro, c) basalt, d) peridotite, e) andesite 
2) Validasi dengan hasil eksperimen

Uji validitas dilakukan dengan cara membandingkan temperatur output program dengan hasil eksperimen yang pernah dilakukan pada penelitian sebelumnya. Pada bagian ini, parameter input nilai resistivitas batuan diubah berdasarkan range nilai resistivitas hasil eksperimen. sesuai jenis batuan yang di tunjukkan pada Tabel 1.

Tabel 1. Nilai resistivitas batuan berdasarkan hasil eksperimen (dimodifikasi dari Telford et al, 1990)

\begin{tabular}{ccc}
\hline Rock & \% H2O & $\boldsymbol{\rho}(\boldsymbol{\Omega m})$ \\
\hline Granite & 0.31 & $4.4 \times 10^{3}$ \\
Granite & 0.19 & $1.8 \times 10^{6}$ \\
\hline Granite & 0 & $10^{10}$ \\
Peridotite & 0.1 & $6 \times 10^{6}$ \\
\hline Peridotite & 0 & $1.8 \times 10^{7}$ \\
Basalt & 0.95 & $4 \times 10^{4}$ \\
\hline Basalt & 0 & $1.3 \times 10^{8}$ \\
Andesite & 0 & $10^{3}-10^{6}$ \\
\hline Gabbro & 0 & $4.5 \times 10^{4}($ wet $)-1.7 \times 10^{2}($ dry $)$ \\
\hline
\end{tabular}

Tabel 2. Nilai temperatur batuan berdasarkan hasil eksperimen (dimodifikasi dari Clauser and Huenges, 1995)

\begin{tabular}{|cc|}
\hline Rock type & T emperature $\left({ }^{0} \mathrm{C}\right)$ \\
\hline Rock salt & $-20-40$ \\
\hline Limestone & $0-500$ \\
\hline Metamorphic rock & $0-1200$ \\
\hline A cid rock & $0-1400$ \\
\hline Basic rock & $50-1100$ \\
\hline Ultra-basic rock & $20-1400$ \\
\hline
\end{tabular}




\section{2. a Granite}

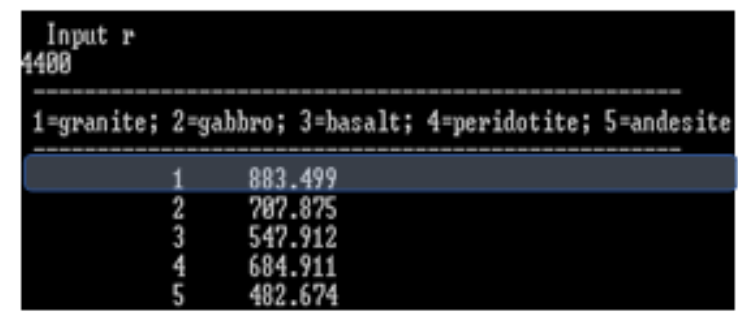

\section{2.b Gabbro}

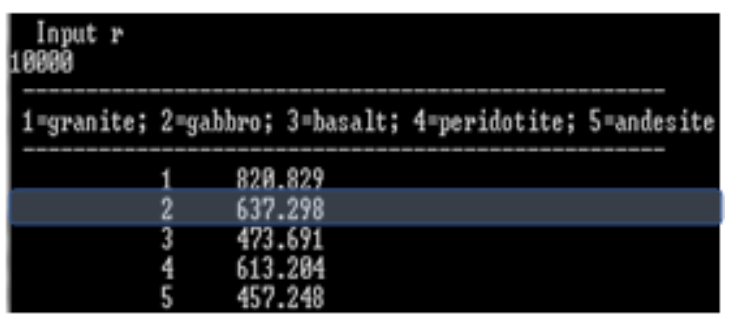

3.2.c Basalt

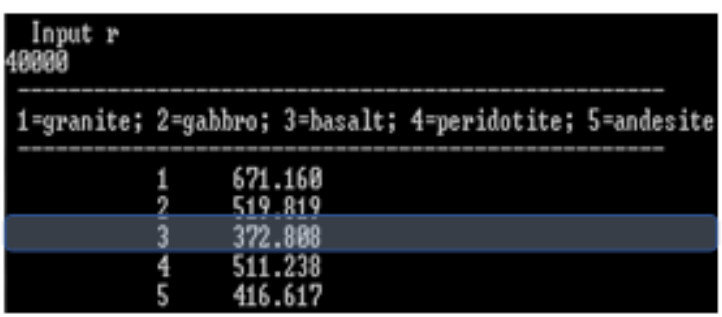

3.2.d Peridotite

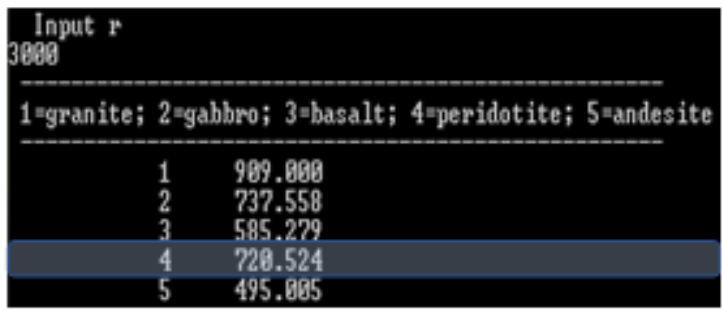

\section{2.e Andesite}

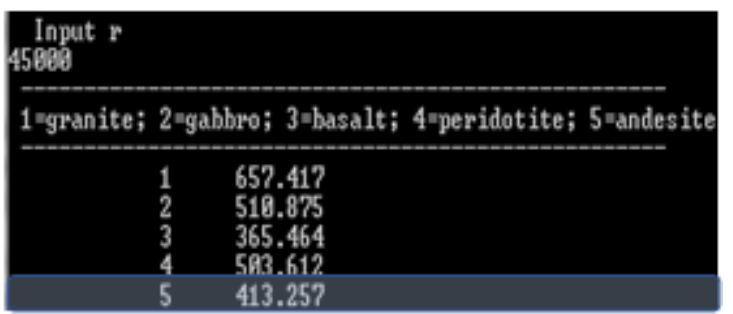

Gambar 4. Tampilan hasil perhitungan program untuk 5 jenis batuan dengan input nilai range resistivitas yang sesuai pada Tabel 1, untuk a) granite, b) gabbro, c) basalt, d) peridotite, e) andesite. 
Hasil temperatur pada output program kemudian disesuaikan dengan temperatur hasil ekperimen. Temperatur batuan hasil eksperimen ditunjukkan pada Tabel 2. Hasil output program menunjukkan bahwa untuk batuan granite dengan memasukkan input resistivitas batuan yang diperoleh secara eksperimen sebesar $4400 \Omega m$ (lihat Tabel 1), maka didapatkan nilai temperatur batuan sebesar 883.5 ${ }^{0} \mathrm{C}$. Begitu pula untuk validasi eksperimen pada batuan lainnya. Pada batuan gabbro dengan memasukkan input resistivitas secara eksperimen sebesar $10000 \Omega$ m, maka didapatkan nilai temperatur batuan sebesar $637.3{ }^{\circ} \mathrm{C}$. Selanjutnya, pada batuan basalt, peridotite dan andesite, dengan memasukkan nilai resitivitas batuan secara eksperimen sebesar $40000 \Omega m, 3000 \Omega m$, dan $45000 \Omega m$, secara berurutan, maka didapatkan nilai temperatur batuan sebesar $372.8{ }^{\circ} \mathrm{C}, 720.5{ }^{\circ} \mathrm{C}$, dan $413.3{ }^{\circ} \mathrm{C}$, secara berurutan. Hasil temperatur output program menunjukkan kesesuaian dengan temperatur hasil eksperimen. Dalam hal ini, nilai temperatur output program berada pada range nilai temperatur pada hasil eksperimen (lihat Gambar 3.2 dan Tabel 2). Meskipun tidak secara jelas dan detail, akan tetapi hasil tersebut memberikan gambaran akan kesesuaian hasil output program dengan hasil eksperimen. Bila dihubungkan kembali, nilai temperatur ke lima jenis batuan tersebut merujuk pada range temperatur untuk 3 jenis batuan yaitu acid rock, basic rock dan ultra-basic rock, yang merupakan karaketristik dari batuan vulkanik yang erat kaitannya dengan manifesto panas bumi (Andrie dkk, 2014).

Hasil validasi program dengan membandingkan hasil perhitungan teoretis dan hasil eksperimen menunjukkan bahwa adanya kelayakan program Boltzmann Temperature Depedence untuk dapat diaplikasikan/dioperasikan untuk mengkonversi parameter nilai resistivitas ke parameter temperatur batuan.

Secara umum, berdasarkan hasil uji validitas, program memiliki beberapa keunggulan diantaranya adalah sebagai berikut; pertama, program sangatlah paraktis. Dikarenakan program secara otomatis mengkonversi nilai resistivitas ke tempatur dengan memasukan parameter input. Kedua, program juga mudah dioperasikan oleh pengguna, bahkan untuk pemula sekalipun. Ketiga, program memiliki nilai error yang rendah dengan tingkat keakurasian yang tinggi. Namun, penulis menyadari ada beberapa kekurangan dalam segi tampilan program, diantaranya adalah sebagai berikut; pertama, interface/tampilan program yang kurang interaktif bagi user (penguna). Hal ini disebabkan tujuan awal program adalah untuk dapat memberikan referensi program bagi peneliti dalam mengkonversi parameter nilai resistivitas batuan ke parameter tempatur batuan. Program tersebut pada dasarnya dibuat bukan untuk tujuan komersil. Kedua, program menampilkan hasil temperatur untuk kelima jenis batuan sekaligus untuk tiap satu input parameter nilai resistivitas batuan. Hal ini disebabkan keterbatasan kemampuan penulis dalam memodifikasi program. Diharapkan kedepannya akan ada tahap pengembangan program tersebut yang dapat memperbaiki kekurangan program pada penelitian ini. 


\section{SIMPULAN}

Berdasarkan analisis hasil yang telah dilakukan maka dapat ditarik kesimpulan antara lain:

1. Berdasarkan hasil validasi, program mungkin dapat dijadikan referensi untuk mengkonversi parameter resistivitas batuan kedalam parameter temperatur batuan.

2. Program Boltzmann Temperature Depedence dapat mengidentifikasi temperatur bawah permukaan pada daerah yang memiliki potensi panas bumi.

\section{UCAPAN TERIMAKASIH}

Terima kasih kepada Tim IUGC Univeritas Brawijaya atas diskusi dalam pemrograman. Program ini dibuat dalam rangka mengikuti kompetisi Indonesia undergraduate geophysics competition (IUGC) 2012 di ITB kategori software competition mewaliki Universitas Brawijaya.

\section{DAFTAR RUJUKAN}

Andrie, A.K., Indarto, S., Permana, H., Gaffar, E.Z., Sudarsono, 2014. Batuan Volkanik Kaitannya dengan Terjadinya Manifestasi Panas Bumi di Permukaan Daerah Guci, Tegal, Jawa Tengah, Prosiding Pemaparan Hasil Penelitian Pusat Penelitian Geoteknologi LIPI.

Clauser, C. and Huenges, E.: 1995, 'Thermal conductivity of rocks and minerals', In: T.J. Ahrens (ed.), A Handbook of Physical Constants, Rock Physics and Phase Relations, Vol. 3, Americal Geophysical Union, Washington DC, pp. 105-125.

Direktorat Jenderal Geologi dan Sumber Daya Mineral, 2004; Berita DJGSM : Pengembangan Energi Panas Bumi, Tanggal 7 Januari 2004.

Herman, Z.D., 2012. Potensi Panas Bumi Dan Pemikiran Konservasinya. Sub Direktorat Konservasi DIM. Pusat Sumber Daya Geologi, Jawa Barat.

Keller, H. J., Ed., 1975. Low-dimensional Cooperative Phenomena. Plenum Press, New York.

Khoirul, U. 2018. Identifikasi litologi bawah permukaan daerah manifestasi panas bumi TinatarKarangrejo kabupaten Pacitan menggunakan metode geomagnet. Fakultas Matematika dan Ilmu Pengetahuan Alam Universitas Negeri Yogyakarta, Yogyakarta.

Rina Wahyuningsih. 2005. Potensi dan wilayah kerja pertambangan panas bumi di Indonesia. Direktorat Inventarisasi Sumber daya Mineral: Kolokium hasil lapangan.

Saptadji, N.M. 2009. Teknik Panas Bumi. Departemen Teknik Perminyakan Fakultas Ilmu Kebumian dan Teknologi Mineral Institut Teknologi Bandung, Bandung.

Telford, W.M., Geldart, L.P., Sheriff, R.E., 1990. Applied Geophysics. Cambridge University Press. Cambridge. 